\title{
Emission and Formation of Fine Particles from Hardcopy Devices: the Cause of Indoor Air Pollution
}

\author{
David D. Massey ${ }^{1 *}$ and Ajay Taneja ${ }^{1,2}$ \\ ${ }^{1}$ School of Chemical Sciences, Department of Chemistry, St John's College, \\ ${ }^{2}$ Department of Chemistry, Dr. B.R. Ambedkar University, \\ India
}

\section{Introduction}

The last few decades have seen major changes in the home and work environments. The economies of the Indian and other industrialized nations have shifted from manufacturing towards services that engage information technologies. Advances in information technology have increased the quantity and transformed the nature of equipment used in proximity to office worker due to which electronic media used for entertainment, telecommunications and data processing have become widespread in daily life. Typical examples are television sets, video recorders, hi-fi systems, and computers with their peripherals such as monitors and printers, scanners and copiers. Tabletop printers serve individual users in their workspace or home, or clusters of users in an office suite. Scanning machines and photocopiers are prevalent in office environments (Newburger, 2001). In addition, the use of notebook computers spanning both work and non work environments is on the rise. These devices are predominantly made of polymeric components and materials which can contain not only additives, such as flame retardants and plasticizers (Wensing et al., 2005), but also chemical residues from production processing aids (Wensing et al., 2002).

There is growing concern about the levels of potentially harmful pollutants that may be emitted from office equipment and for which either toxicological effects or potentially significant exposures have been described in the literature. Office equipment has been found to be a source of ozone, particulate matter, volatile organic compounds (VOCs) and semi volatile organic compounds (SVOCs). VOC, SVOC and particles can also be emitted by the paper processed during printing and copying (Wolkoff et al., 1993). Many studies have investigated the health effects of photocopier toner dust and concluded that siderosilicosis and sarcoidosis-like pulmonary diseases are associated with human exposure to photocopier toner dust (Armbruster et al., 1996). Black and Worthan (1999) have described the VOC/ TVOC, particle and ozone emissions of laser printers, dryprocess photocopiers and personal computers. Wolkoff (1999) study dealt with photocopiers and indoor air pollution. Later on Lee et al. (2001) characterized VOC, ozone and $\mathrm{PM}_{10}$ emissions from office equipment. Today discussion focuses in particular on particle release from hardcopy devices, printers and photocopiers and its impact on the health of office workers (Roller, 2006). Recent advances in measurement techniques have enabled researchers to measure the 
ultrafine particles of nanoscale range and have provided evidence that the smaller particles typically emitted from sources such as internal combustion engines may have more severe impact on the human respiratory system than the bigger particles (Newburger, 2001).

Ozone and particulate matter have been associated with occupational symptoms such as eye, nose or throat irritation, headache and fatigue (Wolkoff et al., 2006). The results of He et al., (2007) suggested that there is potential harm to human beings because of breathed in toner particles. A recent study by Gatti, 2008 using in-vitro and in-vivo experiments with 5 types of nanoparticles found chemical evidence of particulate matter in human pathological tissues from patients who had suffered diseases of unknown origin. It was pointed out in this study that inhaled and ingested nanoparticles can penetrate through the alveolar as well as the digestive walls to enter the blood system and subsequently be transported to any organ in the body. Only about $20 \%$ of nanoparticles are removed once deposited in alveolar regions in animal subjects after 24 hour exposure, in contrast to about $80 \%$ removal for particles above $500 \mathrm{~nm}$ (Oberdörster et al., 2005). In related work, Chalupa et al., (2004) found about $74 \%$ deposition of carbon ultrafine particles in asthmatic human subjects for a 2 hour exposure.

With possible adverse health effects, the question of the chemical characterization of the ultra-fine particles released by such devices is of special importance (BfR, 2008). However, due to the low mass of the UFPs and high volatility nature, they evaporate as soon as they are released; it has not yet been possible to ascertain their chemical composition (Wensing et al, 2008). Previous publications by Bake and Moriske, (2006) and Wensing et al., (2006) have shown that hardcopy devices often emit UFPs while larger particles (e.g. toner dust) could only be detected in low concentrations. Moreover, adverse health effects from exposure to nanoparticles have been found to be more closely related to particle number concentration than to particle mass concentration ( Oberdorster,2000). These health effects may differ substantially depending on the size, morphology, composition (both bulk and surface), and concentration of airborne particles (Oberdorster, 2005).

Many studies of photocopier-related emission have been carried out in test chambers (Lee et al., 2001). Field studies on the impact of photocopiers and printers on indoor air quality are relatively limited. Though specific printer-emitted VOCs and PM has been studied (Kagi et al., 2007), no report has addressed the PM concentration in photocopier and printer centers. Since the size of individual particles influences the degree to which they can be inhaled and the effects that they can cause (Lee et al., 2001), the characteristics of such-emitted particles are needed to evaluate whether exposure control and reduction efforts are necessary. Furthermore, the main difference between the photocopier centers in India and other developed countries is that such centers in India are generally small and serve as both businesses and residences. Thus, the pollutants emitted during such processes would affect the indoor air quality and potentially have adverse health effects on the employees as well as the residents of the workplace. The objective of this study is to investigate size distributed particle number and mass concentration in 250 to 1000 nano meters range in some representative commercial photocopier and printer centers in the Northern Central India. The sources of these particles are also discussed in the indoor air.

\section{Materials and methods}

Air sampling was conducted at 2 photocopier centers A and B (Fig.1) in the Agra city in the month of June 2009. Measurements were made for eight days, four days each at each 
sampling center. In India, most photocopiers and printer centers are located in multi-storey street houses. The area of each center is approximately 30 to $36 \mathrm{~m}^{3}$. No forced ventilation systems used during the measurement. However, the door to the experimental rooms were opened and closed often by the users and the customers whenever they entered the room to use the equipment. In a typical street house, the ground floor is the work area and the upper floors are living areas. Typical interior materials used in photocopier centers include ceramic tile floor, painted concrete ceiling, painted concrete walls and sliding aluminum-framed glass doors. Usually only some metal desks and chairs, and no other furniture are present in the confined space of a photocopier center. Basic information of each center, including business hours, room dimensions, environmental conditions, types of ventilation and entrance, number of photocopiers, printers and number of copies made were collected. Table 1 lists there characteristics of the centers.

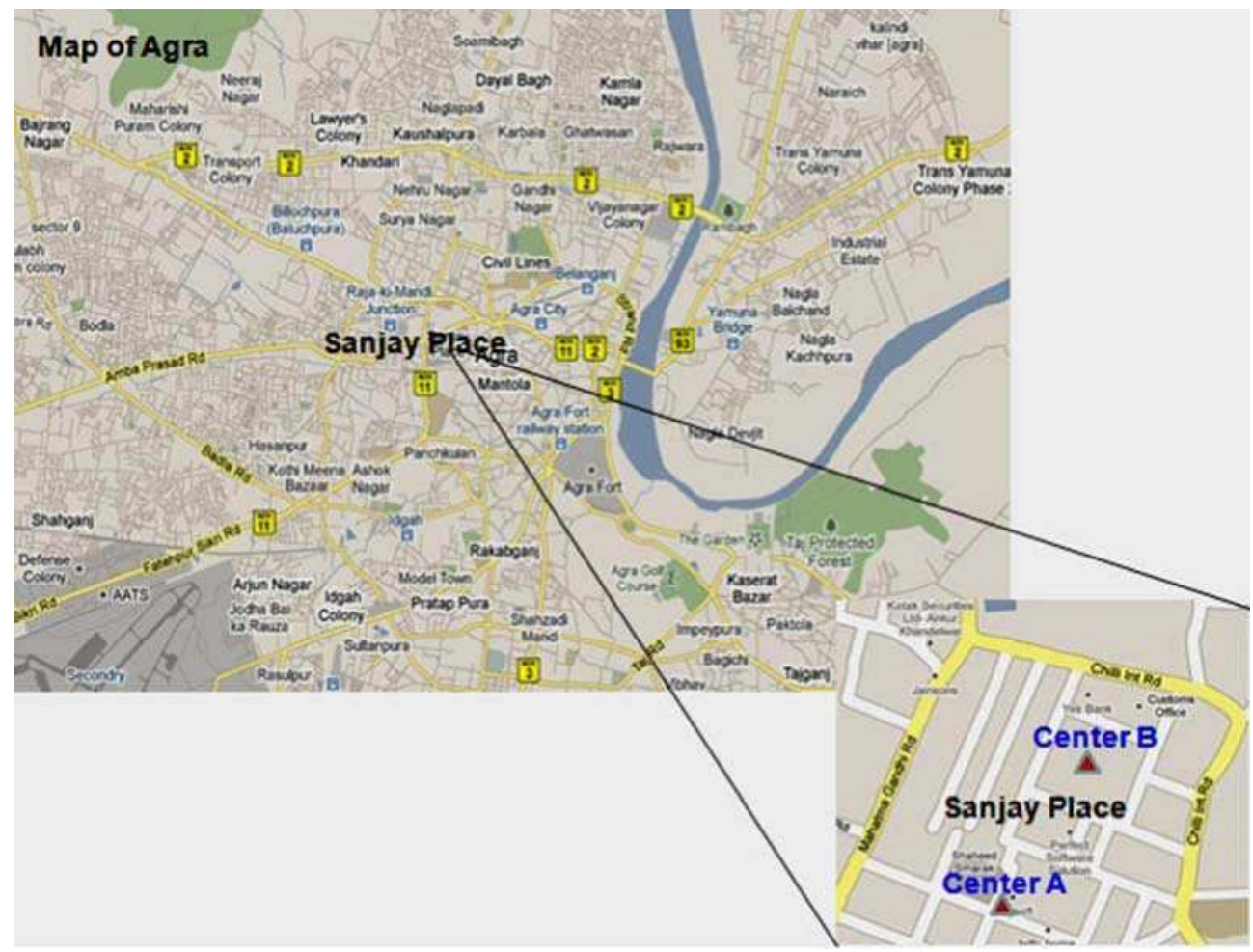

Fig. 1. Map of Agra Showing the Sampling Centers

Grimm 31-Channel Portable Aerosol Spectrometer model No.1.109 was selected for monitoring the particle mass and size distribution in the range of $250-1000 \mathrm{~nm}$, at a flow rate of $1.2 \mathrm{~L} / \mathrm{min} \pm 5 \%$ constant with controller for continuous measurement during the sampling period. The instrument was set to collect data at 10 minute intervals and it store the data in data memory logger card from which data can be downloaded to computer and can be analysed. Particles are collected close by the analyzer from a dedicated $5 \mathrm{~cm}$ long vertical sampling head (no sampling tubes and therefore no particle loss). The instrument 
works on dual technology i.e. the principle of scattering of light at $90^{\circ}$ to give the real-time measurements and total particles can be collected on 47- mm PTFE filter paper for chemical analysis. Its real time measuring range is from $0.25 \mu \mathrm{m}$ to $32 \mu \mathrm{m}$ or $250 \mathrm{~nm}$ to $32,000 \mathrm{~nm}$ in 31 channel sizes, each unit is with NIST (National Institute of Standards and Technology) certified, monodisperse latex on the size of channels calibrated [www. GRIMMaerosols.com].To improve the time resolution, the range was limited to 0.25 to $1 \mu \mathrm{m}$ or 250 to $1000 \mathrm{~nm}$ in 12 channels. The sampling tube of the analyzer was positioned as close as possible to head height in the center of the sampling room. The GRIMM particle measuring system is equipped with GRIMM 1174 Software for data acquisition.

\begin{tabular}{|cccccccc|}
\hline Physical characteristics of the photocopy centers investigated \\
\hline Center & $\begin{array}{c}\text { Room volume } \\
\mathrm{m}^{3}\end{array}$ & $\begin{array}{c}\text { Number of Hardcopiers } \\
\text { Photocopiers }\end{array}$ & $\begin{array}{c}\text { Number of } \\
\text { copies made } \\
\text { Per day }\end{array}$ & $\begin{array}{c}\text { Number of } \\
\text { Measurements } \\
\text { day }\end{array}$ & Type of entrance & Ventilation \\
\hline A & 36 & 1 & 3 & 12500 pages & 4 & push-and-pull door & a \\
B & 30 & 2 & 2 & 7000 pages & 4 & wide-opened door & b \\
\hline
\end{tabular}

$\mathrm{a}=$ air-conditioned, $\mathrm{b}=$ natural ventilation open door

Table 1. Physical Characteristics of the Photocopier Centers

\section{Result and discussion}

\subsection{Experimental methods used in emission characterization}

Sampling was done to measure the ultra fine particle size distribution and mass concentration at an interval of 10 minutes, in two periods at the photocopier and printer centers A and B during the business hours and background hours. The back ground values were obtained inside the centers by monitoring the particles 2 hours before opening of the centre and 2 hours after the centers were closed. All measurements were conducted during eight days period in the month of June 2009. Emissions from hardcopies were measured at room temperature $\left(21-30^{\circ} \mathrm{C}\right)$, with an intermediate humidity conditions $(45-60 \% \mathrm{RH}) . \mathrm{CO}_{2}$ was also recorded up to 650 PPM while sampling.

The average mass concentration of the particles ranged from $1.86 \mu \mathrm{gm}^{-3}$ to $11.71 \mu \mathrm{gm}^{-3}$ at

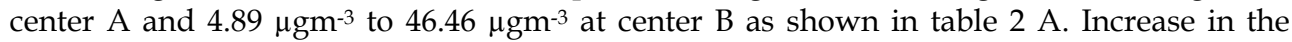
concentration of ultra fine particles in this study seems to be in consistent with the results of studies which suggested that PM emitted by hardcopiers are aerosolized toner powder (Lee et al., 2007). Table $2 \mathrm{~A}$ shows the particle mass concentrations measured in back ground air ranged from $0.87 \mu \mathrm{gm}^{-3}$ to $9.10 \mu \mathrm{gm}^{-3}$ at center $\mathrm{A}$ and $0.87 \mu \mathrm{gm}^{-3}$ to $9.13 \mu \mathrm{gm}^{-3}$ at center $\mathrm{B}$ and during the hardcopier making they ranged from $2.43 \mu \mathrm{gm}^{-3}$ to $13.71 \mu^{-3 \mathrm{gm}^{-3}}$ at center $\mathrm{A}$ and

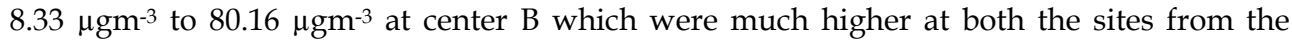
background values. Increase in the particulate concentration at the center B was observed more in comparison to A.

Table $2 \mathrm{~B}$, shows the particle number concentration obtained in photocopier centers A and B. The table reveals that the number of particle increased when hardcopier devices began to make copies. During the operational mode of these hard copying machines the number concentration of the particulate varied in center A from 68223/Lit to 569896/Lit with an average of 258485 / Lit, where as in the center B it varied from 82612/ Lit to 2580941/Lit in the range of 250-1000 $\mathrm{nm}$ with an average of 1504133/Lit respectively. A high number concentration of ultra fine particles was found with a peak value of 569896/Lit particle at 
center A and 1504133/Lit at center B particularly during business hours. The number concentration of particles in 250-1000 nm was significantly higher than mass concentration of the same range at both the centers. It was 3-7 times higher during operational hours than background values obtained before and after the machine was operational at both the centers (table 3). As the machines were nonoperational before the opening of the centers in morning and after the closing of the centers at night, there were significant decrease in the particulate numbers and mass concentrations from the working hours of the machine during the day. While during the working hours, the number of particulate and mass concentration kept on increasing during the first hour of hardcopying; however they decreased after a period of time as shown in Fig. 2.

The number and mass concentrations of the particles in the sampling centers were found to increase significantly from background values during the sampling of $4 \mathrm{hrs}$ in a definite trend as shown in Fig. 2. This increase with respect to background values in centers $\mathrm{A}$ and B was $27 \%$ for first hour which decreased to $23 \%$ in the second hour, $20 \%$ in the third and $19 \%$ in the fourth hour with respect to background values. Thus settling time for the particles emitted from the photocopier was analyzed from the background values measurement. The photocopier and printers were not in use during the night hours that is before opening and after closing of the centers. The total particle count in a cubic centimeter and mass concentration in $\mu_{\mathrm{gm}}{ }^{3}$ of air was estimated for the working hours as shown in Fig 2. Activity resumed from the morning by photo printing of the machines. Hence, the settling time of the particles could be estimated using the data from the background values. It can be seen that the total particle count and mass concentration dropped to low levels over two hours of working and then remained constant during the further working hours.

Centers also have other individual sources than the hardcopiers itself for particles generation. Other chemical constituents, as well as mechanical processes, can also influence the emission behavior during operation (Wensing et al., 2006). Characterizing emissions from hardcopier equipment are also difficult due to the diversity of available equipment, the rapid evolution and turnover of product lines and the variability in environmental and operating conditions. Lee (2001) have pointed out earlier in his laboratory study about $75 \%$ of photocopier toner is transferred to the photoconductive drum and that which does not adhere to the drum becomes available for emission to indoor air. The toner particles are about $10 \mu \mathrm{m}$. It needs further consideration but is indicating (Kagi et al., 2007) in the study that fine particles were not directly generated from toner particles but by the secondary formation of the VOCs and the water mists emitted during the operation of the printers.

Finally, the path by which the UFPs leave the printer is also an important aspect describing emission behavior. As an example, the maximum total concentration of particles $(\mathrm{d}<1 \mu \mathrm{m})$ and the sampling points are displayed by using a printer in Fig.3 (Wensing et al., 2008). The results show that most particles leave the printer near the paper tray and at the back. Release through the fan above the toner waste bottle is considerably lower. Consequently, a retrofitted filter system (designing of air flow system in such a way that the majority of the released UFP leave the casing through a definite opening) may be a possible way to reduce the overall UFP emissions from the appliances. However, the results of this experiment are limited to the printer examined because every type of laser printer-even from the same manufacturer-can have different ventilation and air flow paths. The air flow direction will not be the same for every printer. In some 
cases air is blown into the printer to cool the internal components (such as printed circuit boards). In such a case a fitted filter would only come in contact with the emitted particles via the backflow.

\section{Formation of particles}

The particle size distribution obtained in this study indicated the formation of fine particles during photocopying and printing. Many studies have suggested different mechanism of formation of fine and ultra fine particles (UFP) (Lee et al., 2007).

a. Physical process of nucleation and condensation. The first possible formation mechanism of UFP is the nucleation/condensation of low vapor pressure substances, which were vaporized at high temperature and condensed at low temperature to form particles. Some substances from the heated toner or paper were vaporized during the fusing stage, in which the fuser temperature reached around $200^{\circ} \mathrm{C}$, and their concentrations exceeded their saturation vapor concentration (Jang and Kamens, 2001). Therefore, particles may form when the saturated vapor condenses at a lower temperature.

b. Oxidation of VOCs. The second possible mechanism of UFP formation during photocopying is the oxidation of indoor VOCs. The byproducts of corona charging during photocopying, such as ozone, $\mathrm{NO}_{x}$ and $\mathrm{OH}$-radicals, are both strong oxidants for the oxidations of emitted VOCs. Many studies have demonstrated that photo-oxidation products of aromatic hydrocarbons can undergo various reactions to produce secondary organic aerosols $(\mathrm{SOA})$ in the presence of $\mathrm{O}_{3}, \mathrm{OH}$ radicals, and $\mathrm{NO}_{x}$ (Edney et al., 2001; Jang and Kamens, 2001). The microenvironment inside the photocopier is very similar to a photochemical smog chamber that contains a light source and higher concentrations of reaction agents. Therefore, SOA formation inside photocopiers might be an important source of indoor UFP and FP during photocopying. Furthermore, many studies have confirmed that ozone may react with unsaturated VOCs (such as terpenes and styrene), causing secondary emission of UFP and FP in an indoor environment (Wolkoff and Nielsen, 2001; Fan et al., 2005). Even though UV irradiation is not present in indoor environment (except the spaces inside the photocopiers), SOA may form when ozone reacts with those unsaturated VOCs presented in photocopy center.

c. Ion-induced nucleation. Ions, which are generated by corona devices during photocopying, may play a role in the formation of UFP and FP by ion-induced nucleation of organic vapors. Many works have confirmed the effect of ionizing radiation on aerosol formation (Ramamurthi et al., 1993). Ion-induced nucleation is the gasto-particle process causing supersaturated vapors to condense on ions. During ioninduced nucleation processes, the higher particle growth rates are observed because electrostatic forces would enhance the stability of electrically charged clusters ( $\mathrm{Yu}$ and Turco, 2001). Ichitsubo et al., (1996) reported an experimental study of UFP generated from organic vapors by corona ionizers. Among the organic compounds tested (aromatics, alcohols, ketones and others), only aromatic compounds undergo gas-toparticle conversion process and yield unstable clusters, which may grow into detectable particles $(42 \mathrm{~nm})$ during corona discharge. Based on the results of the above studies, UFP could be formed rapidly during photocopying by the ion-induced nucleation of emitted aromatic hydrocarbons. 
Emission and Formation of Fine Particles from

\begin{tabular}{|c|c|}
\hline 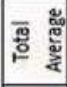 & 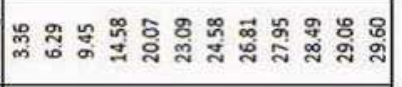 \\
\hline $\begin{array}{l}E \\
\underline{E} \\
\frac{E}{E} \\
\Sigma\end{array}$ & 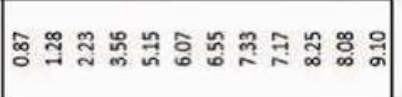 \\
\hline 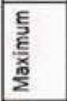 & 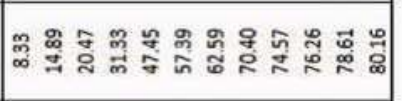 \\
\hline ๕ั้ & ๕ § \\
\hline 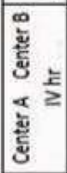 & 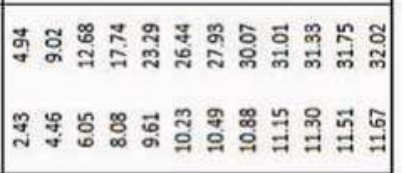 \\
\hline แั้ & 芦 \\
\hline 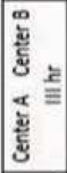 & 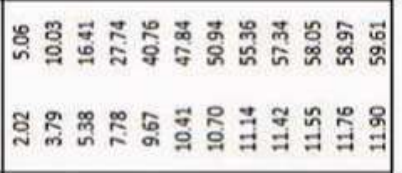 \\
\hline है: & 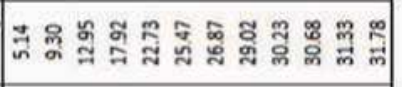 \\
\hline 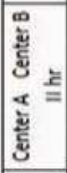 & 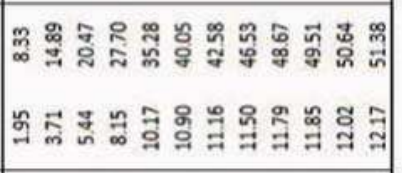 \\
\hline ๕ั้ & 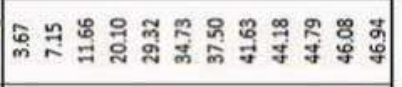 \\
\hline 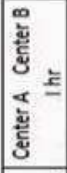 & 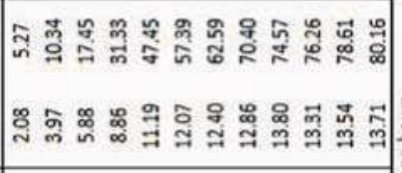 \\
\hline 递 & 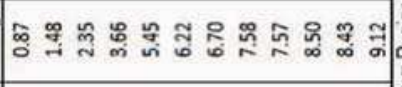 \\
\hline 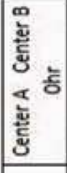 & 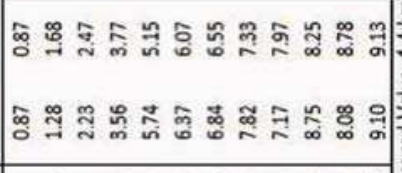 \\
\hline 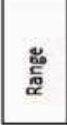 & 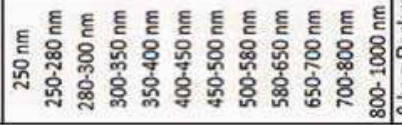 \\
\hline
\end{tabular}

A. Mass concentration in $\mu \mathrm{gm}^{-3}$

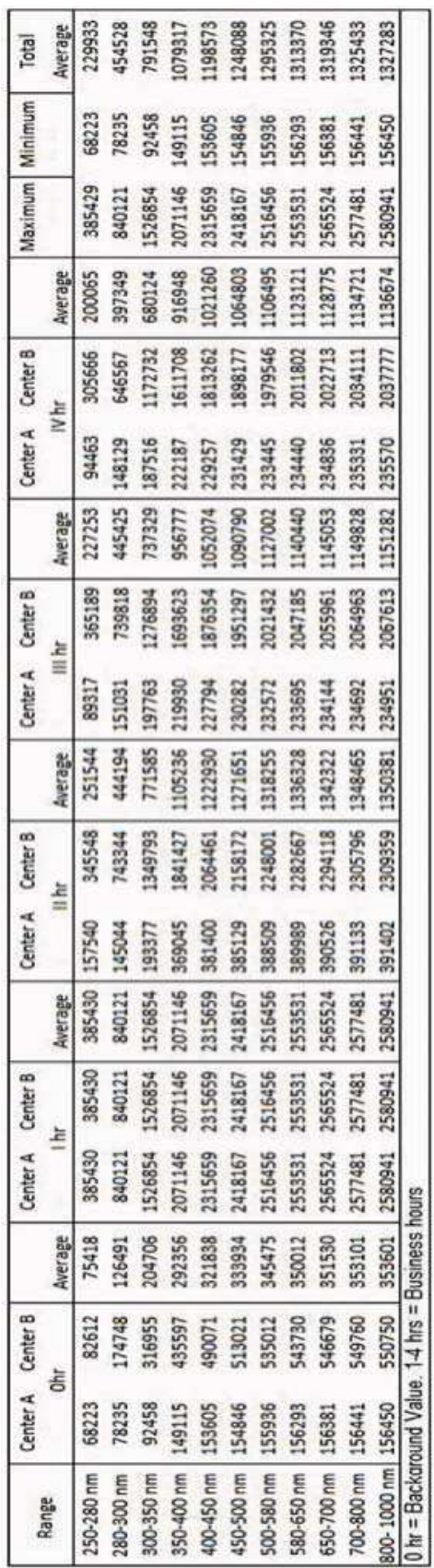

B. Particulate count/liter

Table 2. Particulate Mass and Number at Centers A and B 


\begin{tabular}{|c|c|c|c|c|c|}
\hline Range & $0 \mathrm{hr}$ & $\mathrm{I} \mathrm{hr}$ & $\mathrm{II} \mathrm{hr}$ & $\mathrm{II} \mathrm{hr}$ & $\mathrm{IV} \mathrm{hr}$ \\
\hline $250 \mathrm{~nm}$ & 0.9 & 4.2 & 4.2 & 4.1 & 4.2 \\
$250-280 \mathrm{~nm}$ & 1.5 & 4.8 & 4.7 & 4.7 & 4.5 \\
$280-300 \mathrm{~nm}$ & 2.4 & 5.0 & 4.9 & 4.6 & 4.0 \\
$300-350 \mathrm{~nm}$ & 3.7 & 5.5 & 4.9 & 4.8 & 3.5 \\
$350-400 \mathrm{~nm}$ & 5.5 & 5.4 & 4.2 & 4.6 & 3.0 \\
$400-450 \mathrm{~nm}$ & 6.2 & 5.6 & 4.1 & 4.7 & 2.9 \\
$450-500 \mathrm{~nm}$ & 6.7 & 5.6 & 4.0 & 4.6 & 2.9 \\
$500-580 \mathrm{~nm}$ & 7.6 & 5.5 & 3.8 & 4.4 & 2.7 \\
$580-650 \mathrm{~nm}$ & 7.6 & 5.8 & 4.0 & 4.5 & 2.8 \\
$650-700 \mathrm{~nm}$ & 8.5 & 5.3 & 3.6 & 4.1 & 2.5 \\
$700-800 \mathrm{~nm}$ & 8.4 & 5.5 & 3.7 & 4.2 & 2.6 \\
$800-1000 \mathrm{~nm}$ & 9.1 & 5.1 & 3.5 & 3.9 & 2.4 \\
\hline
\end{tabular}

Mass difference

\begin{tabular}{|c|c|c|c|c|c|}
\hline Range & Ohr & I hr & II hr & III hr & IV hr \\
\hline $250-280 \mathrm{~nm}$ & 75418 & 5.1 & 3.3 & 3.0 & 2.7 \\
$280-300 \mathrm{~nm}$ & 126491 & 6.6 & 3.5 & 3.5 & 3.1 \\
$300-350 \mathrm{~nm}$ & 204706 & 7.5 & 3.8 & 3.6 & 3.3 \\
$350-400 \mathrm{~nm}$ & 292356 & 7.1 & 3.8 & 3.3 & 3.1 \\
$400-450 \mathrm{~nm}$ & 321838 & 7.2 & 3.8 & 3.3 & 3.2 \\
$450-500 \mathrm{~nm}$ & 333934 & 7.2 & 3.8 & 3.3 & 3.2 \\
$500-580 \mathrm{~nm}$ & 345475 & 7.3 & 3.8 & 3.3 & 3.2 \\
$580-650 \mathrm{~nm}$ & 350012 & 7.3 & 3.8 & 3.3 & 3.2 \\
$650-700 \mathrm{~nm}$ & 351530 & 7.3 & 3.8 & 3.3 & 3.2 \\
$700-800 \mathrm{~nm}$ & 353101 & 7.3 & 3.8 & 3.3 & 3.2 \\
$800-1000 \mathrm{~nm}$ & 353601 & 7.3 & 3.8 & 3.3 & 3.2 \\
\hline
\end{tabular}

Count difference

Table 3. Mass and Number Difference at the Two Centers 
Emission and Formation of Fine Particles from

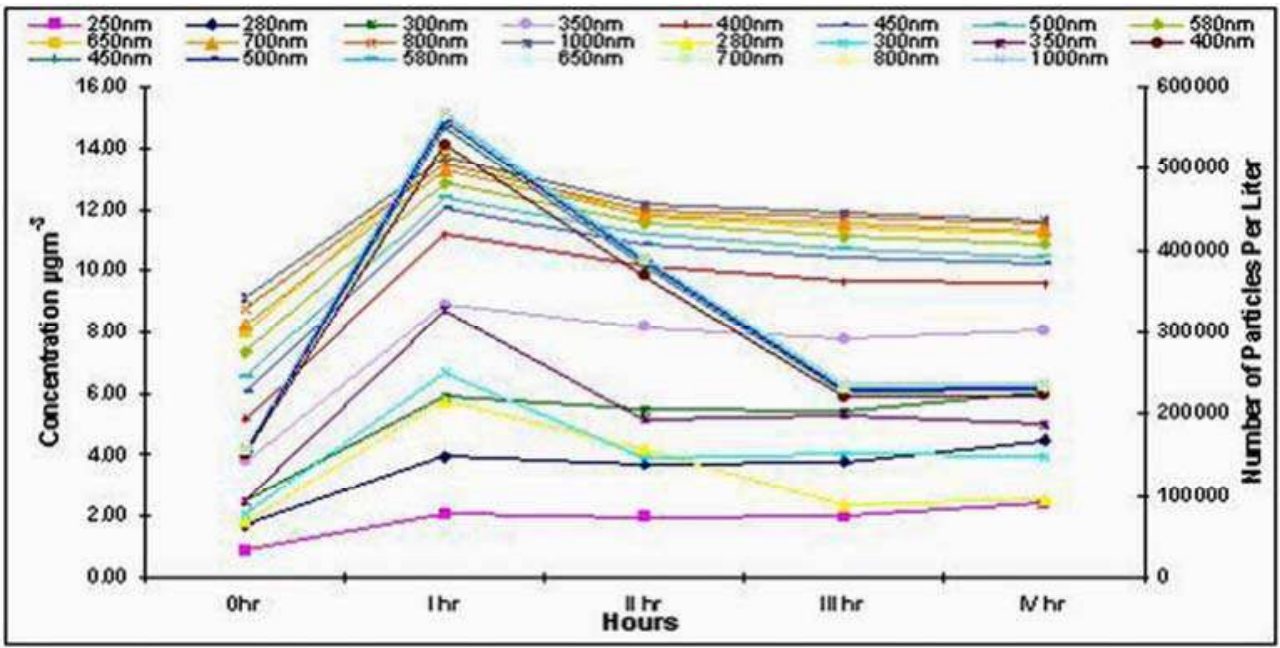

Center A

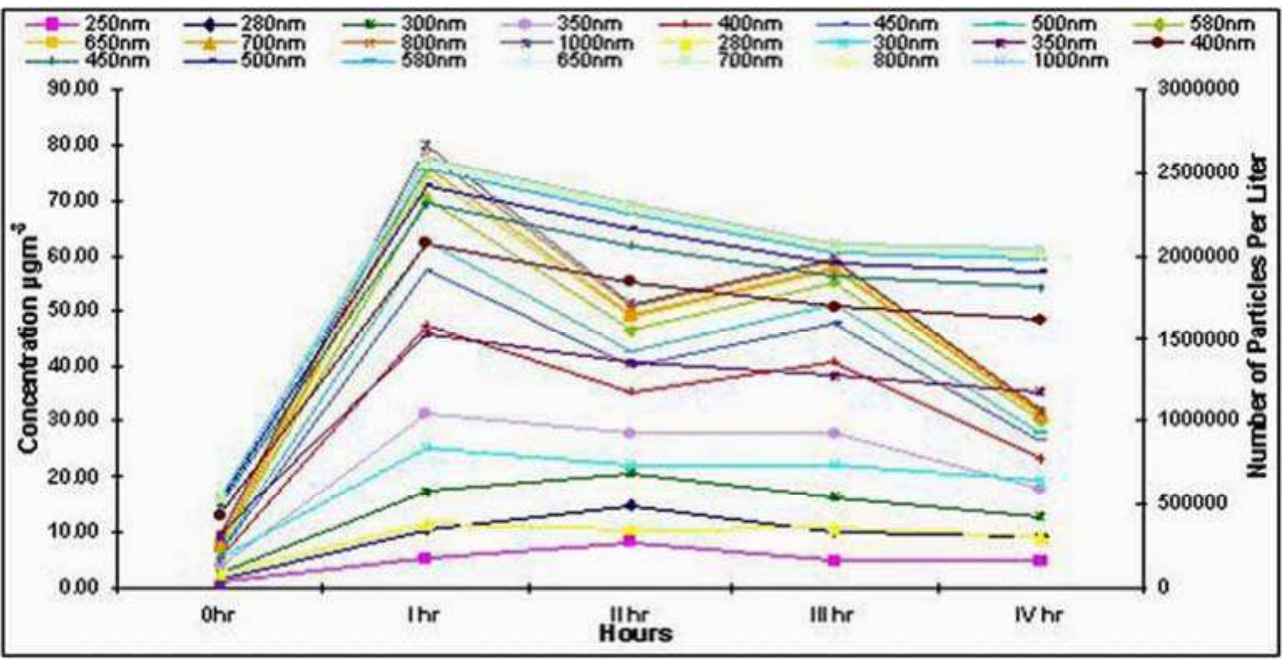

Center B

Fig. 2. Trends in number and mass concentration of particles in photocopier center A and B 
To date, the information regarding the formations of UFP and FP during photocopying is still limited. The mechanism of UFP and FP formation is far from being well understood and a single process is not likely to explain all the phenomena's. Although the formation mechanism remains unclear, Fig. 3 summarizes the possible mechanisms for the formation of UFP during photocopying, including condensation, oxidation and ion-induced nucleation. Corona devices, which can generate ozone, NOx, radicals and ions during photocopying, may be the key element of UFP formation and particle removal in photocopy centers.

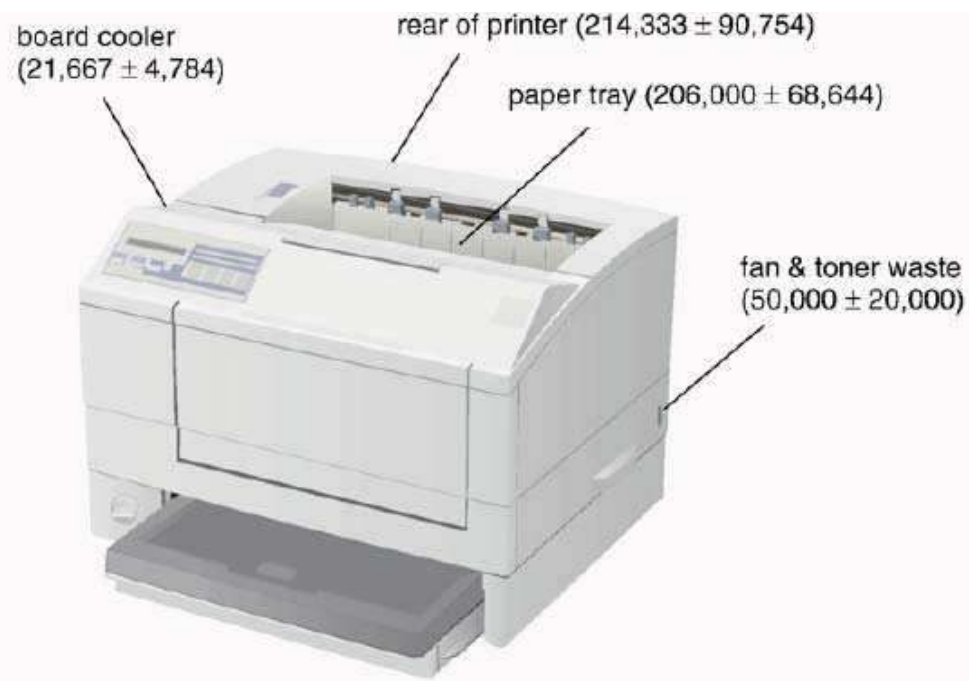

Fig. 3. Example of paths of UFP release from a laser printer Taken from (Wensing et al., 2008)

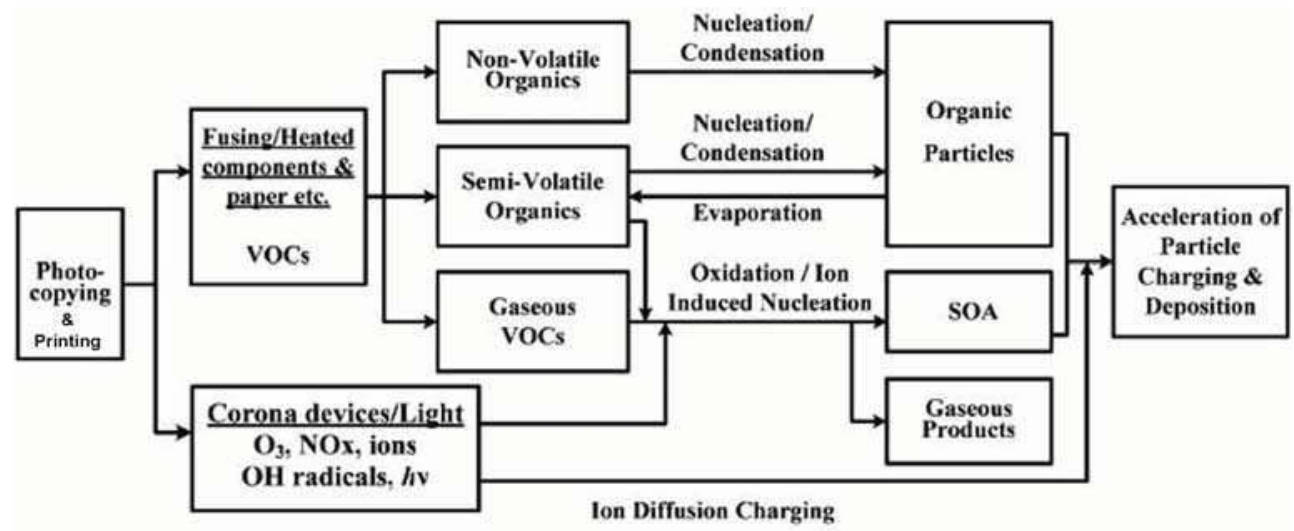

Fig. 4. Conceptual model of indoor air chemistry and particle formation and removal during photocopying and Printing Taken from (Lee et al., 2007) 
Although the formation mechanism remains unclear, Fig.4 summarizes the possible mechanisms for the formation of UFP and FP during photocopying, including condensation, oxidation and ion-induced nucleation (Lee et al., 2007). Corona devices, which can generate ozone, NOx, radicals and ions during photocopying, may be the key element of UFP and FP formation and particle removal in photocopier centers.

\section{Conclusion}

The unexpected phenomenon namely declined in particle mass and number concentration as operation proceeded for few hours is likely attributable to the surface deposition of charged particles, which are charged primarily by the diffusion charging of corona devices equipped inside the hardcopies devices. Particle charging is a function of the ion concentration. Based on the monitored results in centers, particle number and mass concentrations increased immediately as the operations proceeded. During the first hour of operation, ions emitted from corona devices might not be high enough to charge particles indoors; therefore, the increasing trends of particles were consistent. However, after the first hour of operation, the ion concentrations in indoor environment might reach to a point that can accelerate the speed of diffusion charging and increase the deposition rates of charged particles to nearby surfaces. After this point, the particle removal rates were higher than the particle formation rates and therefore the particle number concentrations decreased, although hard copying process was consistently being conducted under the same ventilation conditions. This decrease was less in center A than in comparison to center $B$ because center A was fully air-conditioned. So the doors and windows were kept close where as center B was naturally ventilated.

The results of the these real room measurements are not sufficient to permit classification of possible health related issues with printer and photocopier generated aerosols for this purpose both a more detailed chemical characterization of the particles and a model for exposure assessment would be required. The fact that hardcopy devices are not the only source of fine particulate in indoor environment also needs to be accounted for. In Agra photocopy centers usually open at $10 \mathrm{am}$ and close at $10 \mathrm{pm}$. If the background particulate value is taken as the particle mass concentration in close hours then the $24 \mathrm{~h}$ average PM concentration can be calculated for each photocopy centre by assuming $12 \mathrm{hrs}$ for business and 12 for close hours respectively. Additionally most photocopy centers in Agra open 6 days a week and 52 weeks per year. Therefore based on the results of this study, the PM in the range of $250 \mathrm{~nm}$ to $1000 \mathrm{~nm}$ should be concerned in view of annual human exposure. Personal exposures may be significantly larger than those estimated through average pollutant indoor concentrations, due to proximity of users to the sources over extended periods of time. The magnitude of emissions, the link from emissions to personal exposure, the toxicological significance of the chemicals emitted, and the costs and impacts of alternate materials should all be considered in order to evaluate potential importance of human exposures and health risks. The policy for precautionary reasons for example developing ecolables for low emitting products can be a possible solution to it.

Finally, it is important to put this work in the context of exposure, health implications, energy costs, and technology options. Considering the diversity of equipment, the rapid evolution and turnover of product lines, changes in manufacturing processes and variability 
in operating conditions, the values summarized in this study represent initial estimates of emissions and their implications. This study also highlights the importance the need for evaluating long term effects of exposure to toner particles since these are yet to be fully understood. Further studies are recommended to measure the direct adverse effects of these particles to human health.

\section{Acknowledgements}

The authors like to thank the CSIR (COUNCIL OF INDUSTRIAL RESEARCH) project no: 231065/2K10/1, Dr. F.M.Prasad, Principal of St. John's College Agra and Dr. Ashok Kumar, Head, Department of Chemistry, St. John's College Agra for providing us the facilities.

\section{References}

Newburger E. C. (2001): "Home computers and Internet use in the United States: August 2000 ", Special Studies, US Census Bureau, Washington, DC

Wensing M., Uhde E., Salthammer T. (2005): “Ultra-fine particles release from hardcopy devices: Sources, real-room measurements and efficiency of filter accessories", Science of The Total Environment 339: 19-40

Wensing M., Kummer T., Riemann A., W Schwampe W. (2002): “Emissions from electronic devices: examination of computer monitors and laser printers in a $1 \mathrm{~m}^{3}$ emission test chamber", The 9th International Conference on Indoor Air and Climate, 2, Monterey, p. 554-9

Wolkoff P., Wilkins C.K., Clausen P.A., Larsen K. (1993): “Comparison of volatile organic compounds from processed paper and toners from office copiers and printers: methods, emission rates, and modeled concentrations", Indoor Air, 3: 113-123

Armbruster C., Dekan G., Hovorka A. (1996): “Granulomatous pneumonitis and mediastinal lymphadenopathy due to photocopier toner dust", Lancet 348: 690

Black M.S., Worthan A.W. (1999): "Emissions from office equipment", The $8^{\text {th }}$ International Conference on Indoor Air and Climate. 2, Edinburgh. p. 454-9

Wolkoff P. (1999): "Photocopiers and indoor air pollution", Atmospheric Environment, 33: 2129-30

Lee S.C., Lam S., Fai H.K. (2001): “Characterization of VOCs, ozone, and PM10 emissions from office equipment in an environmental chamber", Building and Environment $369,(7): 837-42$

Roller. (2006): “Quantitative risk assessment for the exposure to toner emissions from copiers", Gefahrst Reinhalt Luft, 66: 211-6

Wolkoff P., Wilkins C.K., Clausen P.A., Nielsen G.D. (2006): “Organic compounds in office environments-sensory irritation, odor, measurements and the role of reactive chemistry", Indoor Air, 16, 7-19

He C., Morawska L., Taplin L. (2007): “Particle Emission Characteristics of Office Printers, Environment Science and Technology, 41 (17)

Gatti A.M. (2008): "Nanopathology: a new vision of the interaction environment-human", Available on line from address: http://ec.europa.eu/research/qualityoflife/ka4/pdf/report_nanopathology_en.pdf 
Oberdorster G., Oberdorster E., Oberdorster (2005): “Nanotoxicology: An emerging discipline evolving from studies of ultrafine particles Environ" J. Health Perspect, 113: 823-839

Chalupa D.C., Marrow P.E., Oberdorster G., Utell M.J., Frampton M.W. (2004): “Ultrafine particle deposition in subjects with asthma", Environmental Health Perspectives. 112: 879-882

BfR-Federal Institute for Risk Assessment, (2008), Gesundheitliche Bewert Organic compounds in office environments - sensory irritation, odor, measurements and the role of reactive chemistry, ung Nr. 014/2008 vom 31, März

Bake D., Moriske H.J. (2006): “Investigations about emissions of fine and ultrafine particles by using laser printers. Umweltmed Forsch Prax 11: 301-8

Wensing M., Pinz G., Bednarek M., Schripp T., Uhde E., Salthammer T. (2006): "Particle measurement of hardcopy devices", Healthy Buildings, 2: Lisbon. pp. 461-464

Oberdorster G. (2000): “Toxicology of ultrafine particles: In vivo studies", Philos.Trans. R. Soc. Lond, A 358: 2719-2740

Oberdorster G., Oberdorster E., Oberdorster (2005): "Nanotoxicology: An emerging discipline evolving from studies of ultrafine particles Environ" J. Health Perspect, 113: 823-839

Kagi N., Fujii S., Horiba Y., Namiki N., Ohtani Y., Emi H., Tamura H., kim Y.S. (2007): "Indoor air quality for chemical and ultrafine particle contaminants from printers", Building and Environment, 42: 1949-1954 www.GRIMM-aerosol.com

Lee C.W., D J Hsu D.J. (2007): "Measurements of fine and ultrafine particle formation in photocopy centers in Taiwan", Atmospheric Environment, 4: 6598-6609

Wensing M., Schripp T., Uhde E., Salthammer T. (2008): “Ultra-fine particles release from hardcopy devices: Sources, real-room measurements and efficiency of filter accessories", Science of The Total Environment, 407: 418-427

Jang M., Kamens R.M. (2001): "Characterization of secondary aerosol from the photooxidation of toluene in the presence of $\mathrm{NO}_{x}$ and 1-propene", Environmental Science and Technology, 35: 3626-3639

Edney E.O., Driscoll D.J, Weathers W.S., Kleindienst T.E., Conver T.S., Mclver C.D., W Li W. (2001): "Formation of polyketones in irradiated toluene/propylene/ $\mathrm{NO}_{\times} /$air mixtures", Aerosol Science and Technology, 35: 998-1008

Wolkoff P., Nielsen G.D. (2001): “Organic compounds in indoor air-their relevance for perceived indoor air quality?", Atmospheric Environment, 35: 4407-4417, 2001

Fan Z.H., Weschler C.J., Han I.K., Zhang J.F. (2005): “Conformation of hydroperoxides and ultra-fine particles during the reactions of ozone with a complex VOC mixture under simulated indoor conditions", Atmospheric Environment, 39: 5171-5182

Ramamurthi M., Strydom R., Hopke P.K., Holub R.F. (1993): “Nanometer and ultrafine aerosols from radon radiolysis", Journal of Aerosol Science, 24: 393-407

Yu F., Turco R.P. (2001): "From molecular clusters to nanoparticles: role of ambient ionization in tropospheric aerosol formation", Journal of Geophysical Research, 106: 4797-4814, 2001 
Ichitsubo H., Alonso M., Ishii M., Endo Y., Kousaka Y., Sato K. (1996): “Behavior of ultrafine particles generated from organic vapors by corona ionizers", Particle and Particle System Characterization, 13: 41-46, 1996 


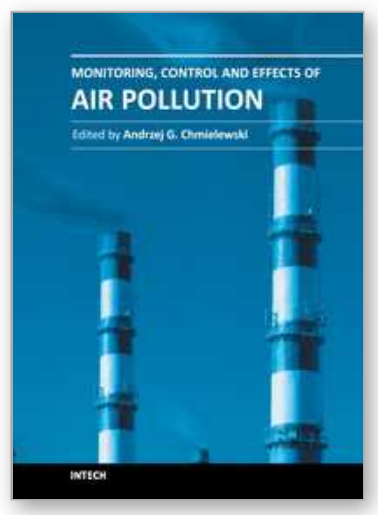

\author{
Monitoring, Control and Effects of Air Pollution \\ Edited by Prof. Andrzej G. Chmielewski
}

ISBN 978-953-307-526-6

Hard cover, 254 pages

Publisher InTech

Published online 23, August, 2011

Published in print edition August, 2011

The book addresses the subjects related to the selected aspects of pollutants emission, monitoring and their effects. The most of recent publications concentrated on the review of the pollutants emissions from industry, especially power sector. In this one emissions from opencast mining and transport are addressed as well. Beside of SOx and NOx emissions, small particles and other pollutants (e.g. VOC, ammonia) have adverse effect on environment and human being. The natural emissions (e.g. from volcanoes) has contribution to the pollutants concentration and atmospheric chemistry governs speciation of pollutants, as in the case of secondary acidification. The methods of ambient air pollution monitoring based on modern instrumentation allow the verification of dispersion models and balancing of mass emissions. The comfort of everyday humanâ $€^{\mathrm{TM}} \mathrm{S}$ activity is influenced by indoor and public transport vehicles interior air contamination, which is effected even by the professional appliances operation. The outdoor pollution leads to cultural heritage objects deterioration, the mechanism are studied and the methods of rehabilitation developed. However to prevent emissions the new technologies are being developed, the new class of these technologies are plasma processes, which are briefly reviewed at the final part of the book.

\title{
How to reference
}

In order to correctly reference this scholarly work, feel free to copy and paste the following:

David D. Massey and Ajay Taneja (2011). Emission and Formation of Fine Particles from Hardcopy Devices: the Cause of Indoor Air Pollution, Monitoring, Control and Effects of Air Pollution, Prof. Andrzej G. Chmielewski (Ed.), ISBN: 978-953-307-526-6, InTech, Available from: http://www.intechopen.com/books/monitoring-controland-effects-of-air-pollution/emission-and-formation-of-fine-particles-from-hardcopy-devices-the-cause-ofindoor-air-pollution

\section{INTECH}

open science | open minds

\author{
InTech Europe \\ University Campus STeP Ri \\ Slavka Krautzeka 83/A \\ 51000 Rijeka, Croatia \\ Phone: +385 (51) 770447 \\ Fax: +385 (51) 686166 \\ www.intechopen.com
}

\author{
InTech China \\ Unit 405, Office Block, Hotel Equatorial Shanghai \\ No.65, Yan An Road (West), Shanghai, 200040, China \\ 中国上海市延安西路65号上海国际贵都大饭店办公楼 405 单元 \\ Phone: +86-21-62489820 \\ Fax: +86-21-62489821
}


(C) 2011 The Author(s). Licensee IntechOpen. This chapter is distributed under the terms of the Creative Commons Attribution-NonCommercialShareAlike-3.0 License, which permits use, distribution and reproduction for non-commercial purposes, provided the original is properly cited and derivative works building on this content are distributed under the same license. 